ANIBAL FAÚNDES ${ }^{1}$

Graciana Alves Duarte ${ }^{2}$ MARIA JosÉ DUARTE OSIS ${ }^{2}$

JORGE ANDALAFt NeTO ${ }^{3}$

Artigos originais

Palavras-chaves

Aborto legal/legislação \& jurisprudência

Aborto criminoso/legislação \&

jurisprudência

Feto/anormalidades

Mortalidade materna

Prática profissional

Conhecimentos, atitudes e prática em saúde

Keywords

Abortion, legal/ legislation \& jurisprudence

Abortion, criminal/ legislation \& jurisprudence

Fetus/abnormalities

Maternal mortality

Professional practice

Health knowledge, attitudes, practice

\section{Variações no conhecimento e nas opiniões dos ginecologistas e obstetras brasileiros sobre o aborto legal, entre 2003 e 2005}

\author{
Knowledge and opinion variations of Brazilian obstetricians \\ and gynecologists face to legal abortion, between 2003 and 2005
}

\title{
Resumo
}

OBJETIVO: avaliar o conhecimento e a opinião de ginecologistas e obstetras acerca do aborto induzido, comparando resultados de dois inquéritos, realizados em 2003 e 2005. MÉTODOS: questionário estruturado e pré-testado enviado a todos associados à Federação Brasileira das Associações de Ginecologia e Obstetrícia (FEBRASGO). Solicitou-se preenchê-lo sem identificar-se e retorná-lo em envelope pré-selado que o acompanhava, com o objetivo de assegurar o anonimato. Perguntou-se sobre conhecimento da legislação referente ao aborto no Brasil e opinião sobre a mesma. RESULTADOS: nos dois inquéritos, a porcentagem de médicos que sabiam quais as circunstâncias em que o aborto não é punido esteve acima de $80 \%$. Porém, houve redução significativa na porcentagem daqueles que conheciam a legalidade do aborto por risco de vida. Aumentou em mais de um terço a proporção de respondentes que sabiam que o aborto por malformação congênita grave não está dentro dos permissivos legais ałuais. Cresceu consistentemente a porcentagem de médicos favoráveis à permissão do aborto em várias circunstâncias, e diminuiu a proporção dos que consideravam que não deveria ser permitido em nenhuma circunstância. Diminuiu a porcentagem dos que opinaram que os permissivos legais não deveriam ser modificados, e aumentou a proporção dos que entendiam que se deveria deixar de considerar o aborto crime em qualquer circunstância. CONCLUSÕES: de modo geral, tem havido maior reflexão sobre o problema do aborto provocado no período transcorrido entre os dois inquéritos. Porém, continua se evidenciando a necessidade de informar corretamente os gineco-obstetras brasileiros sobre as leis e normas que regulamentam a prática do aborto legal no país, visando assegurar que as mulheres que necessitam tenham, de fato, acesso a esse direito.

\section{Abstract}

PURPOSE: to evaluate and compare the knowledge and the opinion of gynecologists and obstetricians regarding termination of pregnancy, in 2003 and 2005. METHODS: a structured and pre-tested questionnaire was sent to all the members of the Brazilian Federation of Gynecologists and Obstetricians (FEBRASGO). They were asked to answer the questions, anonymously, and return the questionnaire in a stamped envelope provided. They were asked about their knowledge of and opinion on Brazilian legislation related to abortion. RESULTS: in both surveys the percentage of doctors who knew under which circumstances abortion was not penalized was over $80 \%$. However, there was a significant reduction in the percentage of doctors who knew that abortion was legal if the woman's life was at risk. The participants who knew that abortion because of a severe congenital malformation of the fetus was not currently permitted by law increased by a third. The percentage of doctors in favor of allowing abortion increased consistently for the various circumstances presented. The proportion of those who thought that abortion should not be permitted in any circumstances decreased. The percentage of those who judged that the legal consents should not be modified decreased. There was an increase in the proportion of those who considered that abortion should not be considered a crime under any circumstance. CONCLUSIONS: in general, it seems that people have been thinking more about induced abortion during the time elapsed between the two surveys. Nevertheless, there is the need to correctly inform Brazilian gynecologists and obstetricians on the laws and norms that regulate the practice of legal abortion in the country, so as to ensure that women who need one have, in fact, access to this right.

Correspondência:

Aníbal Faúndes Cemicamp - Caixa Postal 6181 CEP 13084-971 - Campinas/SP Fone: (19) 3289-2856 - Fax: (19) 3289-2440

E-mail: afaundes@unicamp.br

Recebido

$14 / 02 / 2007$

Aceito com modificacões 05/04/2007
Trabalho realizado no Centro de Pesquisas em Saúde Reprodutiva de Campinas - CEMICAMP - Campinas (SP), Brasil.

' Pesquisador Sênior do Centro de Pesquisas em Saúde Reprodutiva de Campinas - CEMICAMP - Campinas (SP), Brasil; Professor Titular Colaborador Voluntário do Departamento de Tocoginecologia da Faculdade de Ciências Médicas da Universidade Estadual de Campinas - UNICAMP - Campinas (SP), Brasil.

2 Pesquisadora do Centro de Pesquisas em Saúde Reprodutiva de Campinas - CEMICAMP - Campinas (SP), Brasil.

${ }^{3}$ Membro da Comissão Nacional Especializada de Violência Sexual e Aborto Previsto por Lei, da Federação Brasileira das Associações de Ginecologia e Obstetrícia - FEBRASGO - São Paulo (SP), Brasil. 


\section{Introdução}

O aborto é um problema social, pessoal e de saúde pública que afeta a maioria das pessoas, direta ou indiretamente, pelo menos alguma vez na sua vida. Apesar dos esforços parcialmente bem sucedidos de reduzir o número de abortos no mundo e no Brasil, as estimativas globais não têm mudado significativamente. A Organização Mundial da Saúde (OMS) continua informando que há perto de 46 milhões de aborto por ano no mundo. O mais grave é que cerca de 20 milhões desses abortos são qualificados como inseguros, ou seja, realizados por pessoal não qualificado e/ou em condições sanitárias inadequadas ${ }^{1}$. As melhores estimativas para o Brasil variam em torno de 1.000 .000 de abortos anuais, a maior parte deles inseguros ${ }^{2}$.

O grau de segurança sanitária com que se realizam os abortos está intimamente correlacionado com a situação legal no país e o status econômico da pessoa que aborta. A imensa maioria dos abortos inseguros acontece em países onde as leis sobre aborto são muito restritivas, como é o caso do Brasil, e entre as pessoas que não têm condições econômicas para pagar uma clínica, ainda que clandestina, mas bem preparada para realizar abortos seguros.

Ao contrário da crença mais generalizada, o aborto não é penalizado no Brasil em todos os casos. A mulher que se submete ao aborto e o profissional médico que o pratica estão livres de pena se é "a única forma de salvar a vida da mulher grávida" ou se a gravidez é resultado de estupro e a mulher solicita o aborto. Entretanto, até recentemente, era absolutamente excepcional que uma mulher que cumprisse essas condições conseguisse interromper sua gravidez em hospital público num contexto legal.

Por volta de 1990, iniciativas dos municípios do Rio de Janeiro e São Paulo criaram alguns serviços que passaram a realizar abortos em hospitais municipais específicos ${ }^{3}$. Desde 1996, teve início um movimento mais contínuo e nacional, liderado por professores de Ginecologia e Obstetrícia da então Federação Brasileira de Sociedades de Ginecologia e Obstetrícia (hoje Federação Brasileira das Associações de Ginecologia e Obstetrícia, FEBRASGO) e pelo Centro de Pesquisas em Saúde Reprodutiva de Campinas (Cemicamp), com apoio da Rede Feminista de Saúde e Direitos Reprodutivos $^{4}$ e a posterior adesão do próprio Ministério da Saúde e de diversas Secretarias de Saúde Estaduais e Municipais, que tem ampliado o aceso ao aborto legal em quase todo o território nacional ${ }^{5}$.

Uma das dificuldades para o cumprimento da lei é o desconhecimento da população e dos médicos acerca das leis e regulamentos sobre o tema. Isto explica o interesse em saber o grau de conhecimento dos ginecologistas e obstetras sobre estes temas, que motivou um inquérito entre os profissionais associados à FEBRASGO, realizado em 2003, e cujos resultados foram publicados nesta Revista ${ }^{6}$. Esse inquérito revelou algumas falhas no conhecimento da lei por uma porcentagem relativamente alta de médicos, e mais ainda sobre a documentação requerida para a prática do aborto dentro da lei.

Diversos esforços foram feitos pela FEBRASGO, por suas associadas e pelo próprio Ministério da Saúde para melhorar a informação sobre o tema entre os ginecologistas e obstetras ${ }^{7}$. Isto motivou a realização de um segundo inquérito, que permitiu verificar o grau de progresso em conseguir que os associados da FEBRASGO tenham uma melhor e mais completa informação sobre a questão. Além disso, como a atitude dos médicos é também um obstáculo importante para que as mulheres que cumprem os requisitos legais obtenham um aborto em hospital público, consultamos também a opinião dos médicos frente ao aborto. Este trabalho apresenta os resultados deste segundo inquérito, comparando-os com os observados em 2003.

\section{Métodos}

Foi realizado um estudo do tipo inquérito CAP - Conhecimento Atitude e Prática - em 2003, e foi feita uma segunda avaliação em 2005. Para obter as informações, nas duas ocasiões, utilizou-se um questionário estruturado, para ser auto-respondido, que foi pré-testado com médicos ginecologistas e obstetras. Esse questionário continha somente perguntas pré-codificadas, em que deveriam ser assinaladas as alternativas que os participantes julgassem pertinentes.

A seleção dos participantes foi realizada da mesma forma tanto em 2003 quanto em 2005. Primeiramente foi feito o levantamento do número de ginecologistas e obstetras associados à FEBRASGO. O material da pesquisa - uma carta convite, um questionário, um cupom para sorteio e um envelope carta resposta - foi enviado à empresa responsável pela distribuição do Jornal da FEBRASGO, e foi encaminhado aos médicos, na primeira avaliação, juntamente com o Jornal da entidade - Ano 9, No. 10, nov/dez de 2002 - e com o exemplar Ano 10, $\mathrm{N}^{\circ}$. 1, jan/fev de 2003. Na segunda avaliação, o material foi encaminhado com os exemplares: Ano 12, No. 1, jan/fev de 2005 e Ano 12, N ${ }^{\circ}$. 2 , março de 2005 . O objetivo do segundo convite foi aumentar a participação dos ginecologistas e obstetras. Foi necessário enviar novamente o convite a todos os médicos porque não era possível identificar apenas os que não haviam respondido, dadas as medidas adotadas para assegurar o anonimato. 
Entre 10 de fevereiro e 23 de junho de 2003 foram recebidas 4.294 cartas-resposta, sendo que nove médicos devolveram o questionário totalmente em branco. Em 2005, as cartas-resposta começaram a chegar no dia 2 de fevereiro, e até 25 de agosto foram recebidas 3.386 respostas, sendo que 49 médicos devolveram o questionário totalmente em branco. Os questionários preenchidos foram numerados, revisados e arquivados à medida que chegavam. Os dados foram digitados duas vezes, por pessoas distintas, diretamente a partir dos questionários, para que fosse feita a consistência da digitação. Para todos os procedimentos de digitação e checagem foi utilizado o módulo de entrada de dados (DE) do SPSS (SPSS Windows 1993).

A análise dos dados coletados em 2005 foi feita da mesma forma que para os dados de $2003^{6}$. A comparação entre os resultados obtidos em cada oportunidade foi feita utilizando o teste $\chi^{2}$.

A participação dos ginecologistas e obstetras nas duas oportunidades foi voluntária e anônima. Uma vez que as pesquisas abordavam um assunto polêmico e com implicações legais, não foi pedido que os médicos assinassem Termo de Consentimento Livre e Esclarecido, com o objetivo de que não houvesse qualquer informação que identificasse quem respondeu aos questionários. A carta convite de 2003 , bem como a de 2005 , continha esclarecimentos sobre a pesquisa e todas as informações pertinentes que a Resolução 196/96 do Conselho Nacional de Saúde exige ${ }^{8}$. Foi considerado que o fato de responderem às perguntas e enviarem de volta o questionário constituía o consentimento em participar da pesquisa. $\mathrm{O}$ sigilo quanto à fonte das informações foi assegurado ao se identificarem os questionários apenas por um número, que lhes foi atribuído ao serem devolvidos. Os dois protocolos das pesquisas foram aprovados pelo Comitê de Ética em Pesquisas da Faculdade de Ciências Médicas da Universidade Estadual de Campinas (Unicamp).

\section{Resultados}

A distribuição dos respondentes quanto à região de moradia e local de trabalho foi muito similar nas duas ocasiões em que se realizou a pesquisa. A distribuição dos respondentes quanto à região de moradia manteve-se semelhante à dos ginecologistas e obstetras associados à FEBRASGO em geral. O local de trabalho distribuiu-se em partes quase iguais, entre capital e interior. Quanto ao tempo de atuação na área, houve diferença estatisticamente significativa entre os respondentes nas duas ocasiões: em 2003, pouco mais da metade tinha entre mais de 10 e 25 anos de atuação na área, enquanto em 2005 essa proporção correspondeu a um pouco menos que a metade. Cerca de um quarto dos respondentes em 2005 referiu que atuava na área há mais de 25 anos, em comparação com cerca de um quinto dos respondentes de 2003 (Tabela 1).

Tabela 1 - Distribuição percentual dos participantes segundo região de moradia, características do trabalho e influência de sua religião sobre as respostas dadas.

\begin{tabular}{|c|c|c|c|}
\hline Características & $2003^{\#}$ & $2005^{*}$ & $p$ \\
\hline \multicolumn{4}{|l|}{ Regicão de moradia } \\
\hline Norte & $2,8(121)$ & $2,7(91)$ & NS \\
\hline Nordeste & $13,6(579)$ & $14,3(476)$ & \\
\hline Centro-oeste & $6,3(267)$ & $7,4(245)$ & \\
\hline Sudeste & $58,7(2495)$ & $56,7(1881)$ & \\
\hline Sul & $18,6(789)$ & $18,9(627)$ & \\
\hline \multicolumn{4}{|l|}{ Local de trabalho } \\
\hline Capital & $47,0(1982)$ & $49,6(1649)$ & + \\
\hline Interior & $45,2(1907)$ & $48,9(1625)$ & \\
\hline Capital e interior & $7,6(324)$ & $0,9(29)$ & \\
\hline Aposentado & $0,2(7)$ & $0,7(22)$ & \\
\hline \multicolumn{4}{|l|}{ Tempo de atuação na área } \\
\hline Até 10 anos & $26,0(1087)$ & $25,0(832)$ & $<0,001$ \\
\hline Mais de 10 ałé 25 anos & $51,9(2171)$ & $49,1(1631)$ & \\
\hline Mais de 25 anos & $22,1(924)$ & $25,9(859)$ & \\
\hline \multicolumn{4}{|c|}{ Influência da religião sobre as repostas } \\
\hline Muito importante & $28,6(1193)$ & $27,0(864)$ & \\
\hline Pouco importante & $26,0(1087)$ & $38,7(1239)$ & \\
\hline Não importante & $34,8(1454)$ & $22,1(707)$ & \\
\hline Sem religião & $10,6(441)$ & $12,3(395)$ & \\
\hline Tołal & 4261 & 3337 & \\
\hline
\end{tabular}

\#Faltou informação de dez médicos para região de moradia, de 41 para localidade onde trabalha, de 79 para tempo de atuação na área e influência da religião. Um médico não soube definir a importância de sua religião e seis deram outras respostas.

*Faltou informação de 17 médicos para região de moradia, de 12 para localidade onde trabalha, de 15 para tempo de atuação na área e de 59 para importância da religião. Um médico não soube definir a importância de sua religião e 72 deram outras respostas.

+Não foi possível aplicar o teste estatístico porque as perguntas foram formuladas de forma diferente.

NS=não significante. 
Em 2005, houve pequena diminuição na proporção de respondentes que declararam que a religião foi muito importante para suas respostas, mas, em compensação, houve um aumento bem maior, de quase 13 pontos percentuais, na porcentagem que declarou que a religião foi pouco importante, e uma redução da mesma dimensão dos que declararam que a religião não foi importante. Essas diferenças foram estatisticamente significativas (Tabela 1).

Observou-se que o conhecimento sobre a legalidade do aborto em caso de gravidez por estupro manteve-se alto em 2005, acima de $90 \%$, mas em relação ao aborto por risco para a vida da mulher, o conhecimento da legalidade diminuiu em pouco mais de seis pontos percentuais. Também em 2005, o conceito errôneo de que o aborto de fetos com malformações graves incompatíveis com a vida extra-uterina estava contemplado pela lei foi reduzido em mais de um terço, caindo de mais de $30 \%$ a menos de $20 \%$ dos respondentes. Essas diferenças foram significativas. Tal como na ocasião anterior, em 2005 , bem poucos respondentes afirmaram erroneamente que existiam outras condições em que o aborto não é punível (Tabela 2).

Quanto à opinião dos respondentes acerca das situações em que o aborto deveria ser permitido, houve aumento significativo e consistente na proporção de médicos favoráveis à realização do aborto em cada uma das circunstâncias apresentadas nas duas oportunidades: quando a gravidez for resultante de estupro, a proporção de médicos favoráveis subiu de 77 para 85\%; por risco de vida ou em caso de malformação fetal grave, de me- nos de 80 para 90\%; quando a mulher for solteira e o parceiro não assume, de dois para $11 \%$; por problemas financeiros, de seis para $12 \%$; e em caso de mulher HIV positiva, de 13 para $18 \%$. A porcentagem de médicos que opinaram que o aborto não deveria ser permitido em nenhuma circunstância diminuiu de quatro para $3 \%$, e essa diminuição foi significativa. Entretanto, não houve diferença nas proporções de médicos que opinaram que o aborto deveria ser permitido em qualquer circunstância, que foi de cerca de $10 \%$ nas duas ocasiões em que a pesquisa foi realizada (Tabela 2).

Além disso, em 2005 , pouco mais de $60 \%$ dos respondentes se manifestaram de acordo com que fosse permitido legalmente o aborto em caso da gravidez trazer prejuízos graves à saúde física da mulher, e quase $40 \%$ se trouxer prejuízos graves à saúde psíquica (Tabela 3). Não foi possível comparar esses resultados com 2003 porque, naquela ocasião, essas circunstâncias não foram apresentadas aos respondentes para darem sua opinião.

Quando perguntados sobre uma possível mudança na atual legislação referente ao aborto, cerca de $66 \%$ dos participantes nas duas oportunidades $(65,4 \% \mathrm{em}$ 2003 e 66,6\% em 2005) opinaram que as circunstâncias em que o aborto não é punido deveriam ser ampliadas. Porém, em 2005 houve um leve aumento de dois pontos percentuais dos que opinaram que o aborto nunca deveria ser crime, subindo de $14,4 \%$ em 2003 a 16,4\% neste último ano. Por outro lado, diminuiu a proporção daqueles que consideravam que

Tabela 2 - Proporção de participantes segundo conhecimento e opinião sobre as circunstâncias nas quais a lei brasileira não pune 0 aborto praticado por médico.

\begin{tabular}{|c|c|c|c|c|c|c|}
\hline \multirow[b]{2}{*}{ Circunstâncias } & \multicolumn{3}{|c|}{ Conhecimento } & \multicolumn{3}{|c|}{ Opinic̃o } \\
\hline & $2003^{\#}$ & $2005^{*}$ & $p$ & $2003^{\#}$ & $2005^{*}$ & p \\
\hline Gravidez resultante de estupro & $92,8(3928)$ & $93,4(2937)$ & NS & $76,6(3217)$ & $84,8(2801)$ & $<0,000$ \\
\hline Em caso de risco de vida da gestante & $89,3(3781)$ & $82,9(2607)$ & $<0,000$ & $79,3(3330)$ & $90,5(2990)$ & $<0,000$ \\
\hline Gravidez traz prejuízos graves à saúde física da mulher\& & & $20,6(647)$ & & & $61,4(2028)$ & \\
\hline Feto com qualquer malformação congênita grave & $31,8(1346)$ & $19,6(617)$ & $<0,000$ & $77,0(3233)$ & $90,0(2975)$ & $<0,000$ \\
\hline Diagnóstico de anencefalia ${ }^{\&}$ & & $19,6(617)$ & & & $89,9(2971)$ & \\
\hline Gravidez traz prejuízos graves à saúde psíquica da mulher & & $1,8(57)$ & & & $38,8(1281)$ & \\
\hline Mulher solteira e parceiro não assumem gravidez ${ }^{\&}$ & $0,2(10)$ & $0,2(5)$ & NS & $2,1(90)$ & $10,8(356)$ & $<0,000$ \\
\hline Mulher ou parceiro HIV positivo & $0,5(20)$ & $0,2(5)$ & $<0,04$ & $12,7(532)$ & $17,6(580)$ & $<0,000$ \\
\hline Mulher não tem condições financeiras de ter o bebê & $0,1(6)$ & $0,1(4)$ & NS & $6,4(268)$ & $12,1(400)$ & $<0,000$ \\
\hline $\begin{array}{l}\text { Mulher sem condições psicológicas/ } \\
\text { emocionais de ter o beb } \hat{e}^{+}\end{array}$ & $0,4(19)$ & & & $17,4(731)$ & & \\
\hline Falha do MAC em uso ${ }^{+}$ & $0,1(5)$ & & & $4,1(172)$ & & \\
\hline Em qualquer circunstância & & & & $9,9(415)$ & $9,7(321)$ & NS \\
\hline Em nenhuma circunstância & & & & $4,5(190)$ & $3,1(101)$ & 0,002 \\
\hline Total & 4233 & 3145 & & 4200 & 3304 & \\
\hline
\end{tabular}

\#Faltou informação de 28 médicos para conhecimento e de 61 médicos para opinião.

*Faltou informação de 175 médicos para conhecimento, dois não souberam informar e 15 citaram exclusivamente outras situações.

Faltou informação de 21 médicos para opinião e 12 deram exclusivamente outras respostas.

+Circunstância apresentada somente em 2003.

\&Circunstância apresentada somente em 2005

$\mathrm{MAC}=$ método anti-concepcional; $\mathrm{NS}=$ não significante. 
a lei não deveria ser modificada: 13,4\% em 2003 e $5,5 \%$ em 2005. Aumentou a porcentagem dos que opinaram que o aborto sempre deveria ser proibido ou deveriam aumentar as restrições, passando de 0,2\% em 2003 a 7,5\% em 2005. Essas diferenças foram significativas (dados não incluídos em tabela).

Em 2003, dois terços dos respondentes afirmaram que havia necessidade de alvará judicial para realizar um aborto legal. Em 2005, pouco mais de um terço continuava acreditando na necessidade desse documento para realizar legalmente um aborto em caso de gravidez por estupro, e $50 \%$ em caso de risco de vida. No sentido contrário, aumentou consideravelmente a proporção de participantes que acreditavam que eram necessários boletim de ocorrência policial (BO) e laudo do Instituto Médico Legal (IML) em caso de estupro: de 42 para $69 \%$ e de 28 para $46 \%$, respectivamente. A proporção de médicos que considerava necessária a solicitação por escrito da gestante aumentou bastante, mas manteve-se abaixo de 50\%: em 2003 foram 27\% para aborto legal e, em 2005 , foram respectivamente 40 e $47 \%$ para risco de vida e estupro. Algo semelhante foi observado quanto à necessidade de autorização por escrito do pai/responsável, caso a mulher tenha menos de 21 anos: houve um aumento, passando de pouco mais de $20 \%$ em 2003 no caso de aborto legal, a cerca de $30 \%$ para risco de vida e $36 \%$ para estupro, em 2005 (Tabela 3).

Em relação aos documentos necessários para realizar o aborto nos casos de malformação fetal grave, não houve diferença ao comparar as respostas dos participantes em 2003 e 2005, quanto à apresentação de laudo de três médicos, apontada por cerca de $44 \%$ nas duas ocasiões. Aumentou em 2005 a porcentagem de médicos que disseram ser necessária a solicitação da própria gestante - de 28 para 35\%; dos que referiram a necessidade de autorização por escrito do pai/responsável quando a mulher tiver menos de 21 anos - de 19 para 22\%. Por outro lado, diminuiu a proporção de participantes que disseram ser necessário alvará judicial para realizar o aborto nesses casos - de 79 para $60 \%$; e daqueles que não sabiam quais documentos eram necessários - de oito para $2 \%$. Essas diferenças foram estatisticamente significativas (Tabela 3 ).

Observou-se uma consistente diminuição entre 2003 e 2005 na porcentagem de médicos que responderam quantas vezes mais que o normal deveria ser a letalidade da doença durante a gravidez para justificar a interrupção da gestação por risco de vida. Os que opinaram que se justificava se o risco for duas vezes ou mais que o normal caiu de 37 para 27\%; com risco cinco vezes maior passou de 24 para 19\%; com risco dez vezes maior, de 16 para $11 \%$; com risco 20 vezes maior que o normal, de 2,5 para $2 \%$; e com risco 50 vezes maior que o normal, de sete para $3,6 \%$. A porcentagem que afirmou que nunca se justifica caiu de 12 para $9 \%$, enquanto aumentou consideravelmente a proporção dos respondentes que declararam não ter opinião formada: de 1,5 para $28 \%$. As diferenças foram significativas $(\mathrm{p}<0,000)$.

Tabela 3 - Opinião acerca dos documentos a serem apresentados pela mulher para obtenção do aborto nos casos previstos em lei e no caso de malformação fetal grave (em percentagem).

\begin{tabular}{|c|c|c|c|c|c|c|}
\hline \multirow[b]{2}{*}{ Documentos } & \multirow{2}{*}{$\begin{array}{c}\text { Previsto em lei } \\
2003^{\#}\end{array}$} & \multirow{2}{*}{$\begin{array}{r}\begin{array}{r}\text { Risco de vida } \\
\text { da gestante }\end{array} \\
2005^{*}\end{array}$} & \multirow{2}{*}{$\begin{array}{c}\text { Gravidez resultante } \\
\text { de estupro }\end{array}$} & \multicolumn{2}{|c|}{ Malformação fetal } & \multirow[b]{2}{*}{$\mathrm{p}$} \\
\hline & & & & $2003^{\#}$ & $2005^{*}$ & \\
\hline Alvará judicial & $66,2(2799)$ & $36,1(952)$ & $50,5(1390)$ & $79,2(3335)$ & $60,1(1400)$ & $<0,000$ \\
\hline Laudo de três médicos & $47,3(2002)$ & $86,4(2275)$ & $18,5(510)$ & $44,2(1863)$ & $43,7(1018)$ & NS \\
\hline Boletim de ocorrência & 42,0 (1778) & $3,3(86)$ & $68,8(1895)$ & & $1,8(43)$ & \\
\hline Laudo do Instituto Médico Legal & $28,1(1188)$ & $1,1(28)$ & $46,1(1271)$ & & $0,6(13)$ & \\
\hline Solicitação por escrito, de próprio punho e assinada & $27,4(1157)$ & $39,5(936)$ & $47,0(1294)$ & $28,4(1196)$ & $34,8(812)$ & $<0,000$ \\
\hline $\begin{array}{l}\text { Autorização por escrito do pai/responsável, } \\
\text { caso a mulher tenha menos de } 21 \text { anos }\end{array}$ & $22,4(947)$ & $28,2(744)$ & $36,4(1002)$ & $19,4(818)$ & $21,6(504)$ & $<0,037$ \\
\hline Situação não prevista na lei & & $4,0(105)$ & $1,3(36)$ & & $30,2(703)$ & \\
\hline Não sabe & $6,1(258)$ & $2,4(64)$ & $1,3(36)$ & $7,8(327)$ & $1,5(51)$ & $<0,000$ \\
\hline Nada & $1,3(57)$ & & & $2,4(103)$ & & \\
\hline Nada porque não é atendido; ilegal & & & & $0,3(11)$ & & \\
\hline Total & 4229 & 2634 & 2755 & 4212 & 2331 & \\
\hline
\end{tabular}

\#Faltou informação de 32 médicos para os casos previstos em lei e de 49 para o caso de malformação fetal grave.

*Faltou informação de 703 médicos para risco de vida da gestante, de 582 para gravidez resultante de estupro e de 1006 para o caso de malformação fetal grave. NS=não significante 


\section{Discussão}

Os resultados deste segundo inquérito entre ginecologistas e obstetras afiliados à FEBRASGO indicam que, de modo geral, tem havido maior reflexão sobre o problema do aborto provocado nos dois anos transcorridos entre as duas pesquisas - 2003 e 2005 . Aumentou em mais de um terço a proporção de médicos respondentes que sabiam que o aborto por malformação congênita grave incompatível com a vida extra-uterina, apesar de cada vez mais acessível por autorização judicial, não está incluída nas permissões legais do Código Penal vigente desde 1940. Surpreendeu um pouco a redução na porcentagem daqueles que conheciam a legalidade do aborto por risco de vida, mantendo-se, entretanto, acima de $80 \%$, e não nos ocorre uma explicação para essa observação.

Apesar de ter melhorado o conhecimento acerca da não necessidade de alvará judicial nos casos permitidos pela lei, é lamentavelmente elevada a porcentagem de médicos que ainda acreditam que esse documento é necessário nesses casos, mostrando o muito que ainda há por fazer para melhorar a informação dos ginecologistas e obstetras brasileiros quanto a esses aspectos.

Chama particularmente atenção o grande aumento, entre 2003 e 2005, na porcentagem de participantes que consideram ser necessário $\mathrm{BO}$ e laudo do IML para cumprir os preceitos legais no caso de aborto de gravidez por estupro. A mais provável explicação para isso é o parecer do Conselho Federal de Medicina (CFM) respaldando essa exigência do $\mathrm{BO}$, embora a Norma do Ministério da Saúde seja explícita em destacar que a lei não inclui essa exigência ${ }^{7}$. O que era apenas uma recomendação do CFM foi, provavelmente, confundido com uma exigência, mostrando a necessidade de que o CFM e os Conselhos Regionais de Medicina esclareçam rapidamente esse ponto, pois acarreta mais um obstáculo que impede as mulheres brasileiras estupradas de terem acesso a seus direitos legais.

Os operadores da lei também têm deixado repetidamente claro que o laudo do IML, bem como o BO, são necessários apenas para o processo legal, caso a mulher queira denunciar ou processar o agressor, o que é seu direito, mas não a sua obrigação, e que a mulher deve ter liberdade para decidir se quer ou não esses documentos 9 . Não se justifica, portanto, a exigência do BO ou do laudo do IML para que os hospitais e os médicos apliquem a lei e realizem o aborto no caso da mulher estuprada que o solicita.

Os resultados também mostram que aumentou, de 2003 a 2005, a porcentagem dos gineco-obstetras que se posicionaram favoravelmente à permissão legal do aborto nos casos já incluídos na lei e na jurisprudência dos últimos anos, isto é, quando há risco de vida para a mãe, gravidez por estupro e malformação congênita incompatível com a vida, incluindo especificamente a anencefalia ${ }^{10}$. Verificou-se aumento na aceitação de incluir nos permissivos legais as circunstâncias em que a mãe é solteira e abandonada pelo parceiro, casos de soro-positividade para HIV e razões financeiras, mas sempre com porcentagem de aceitação abaixo de $20 \%$. Além disso, em 2005, quando apresentadas aos respondentes novas circunstâncias, mais de $60 \%$ dos médicos foram favoráveis a que a lei permita o aborto quando a gravidez representa uma grave ameaça para a saúde física da mulher, e $40 \%$ quando ameace a saúde psíquica da grávida.

É importante esclarecer que os achados acima não devem ser interpretados como se houvesse um aumento na porcentagem de médicos "a favor do aborto". Não há nenhum indício nas respostas que permita suspeitar que os respondentes gostem que se pratique ou que eles mesmos praticassem. O que ocorre é um aumento na compreensão (e aceitação) de que existem certas situações em que não se justifica obrigar a mulher a realizar o aborto na clandestinidade, como em caso de gravidez por estupro, ou a colocar em perigo sua vida e sua saúde, como nos casos de risco para a vida da mulher ou para sua saúde física ou psíquica.

As mudanças para menos na porcentagem de participantes que responderam positivamente à pergunta mais detalhada sobre aborto por risco de vida - "quanto maior a letalidade durante a gravidez provocada por uma doença prévia tem que ser para que o aborto se justifique?" parece-nos indicar uma tendência a meditar mais sobre essas circunstâncias. Isto fica mais claramente sugerido pelo enorme aumento, de pouco mais de $1 \%$ em 2003 a 28\% em 2005, daqueles médicos que declararam que não tinham opinião formada. A elevada proporção de médicos que deram essa resposta sugere que, em 2005, um grupo bem maior de profissionais passou a entender a necessidade de uma análise mais profunda desse dilema, em comparação com 2003.

A marcada redução, de 13,5\% em 2003 para 5,5\% em 2005, dos que opinaram que a lei sobre aborto não deve mudar, também nos mostra que há maior reflexão sobre o tema. As pessoas estão com posições mais meditadas, levando a um pequeno aumento de três pontos percentuais, até $83 \%$, entre os que acham que o aborto deveria ser descriminalizado ou que se deveria ampliar os permissivos legais. Ao mesmo tempo, aumentou de menos de um para $7,5 \%$ os que opinaram que o aborto deve ser totalmente proibido ou devem ampliar-se as restrições ao aborto legal. A porcentagem 
dos que declararam sem opinião, que desceu de mais de seis para menos de $4 \%$, confirma a maior reflexão sobre o problema.

O que nos parece profundamente decepcionante é a alta porcentagem de médicos que não dão importância à solicitação da mulher ou de seu representante legal, se menor, nas diferentes situações de aborto legal. A proporção dos que acreditaram ser necessário a solicitação por escrito da mulher aumentou de menos de 30\% em 2003 para cerca de $35 \%$ (para malformação) até $47 \%$ (para gravidez por estupro) em 2005. As porcentagens são ainda piores no caso de menores. Em 2005, a autorização do responsável legal foi considerada necessária por aproximadamente $30 \%$ para o caso de risco de vida, por cerca de $22 \%$ para malformação e $36 \%$ em caso de estupro.

Julgamos que há duas possíveis explicações para estes achados: uma seria que mais da metade dos participantes acreditavam ser desnecessário considerar a opinião da pessoa afetada por suas ações quando se trata de uma decisão tão difícil como é a interrupção de uma gravidez. A outra, é que consideravam ser suficiente a solicitação verbal, e que não é necessário deixar registrado que a iniciativa de interromper a gravidez foi da própria mulher. No primeiro caso seria um desconhecimento lamentável de princípios éticos básicos como o de respeito à autonomia das pessoas ${ }^{11} \mathrm{e}$, no segundo, um risco importante ao assumir uma grande responsabilidade sem o respaldo escrito da pessoa afetada.

Poderiam colocar-se dúvidas quanto à validade da comparação entre os que participaram em 2005 e os que tinham respondido em 2003, já que não são necessariamente as mesmas pessoas. Entretanto, as características dos entrevistados em 2003 e 2005 foram muito similares. Houve diferença quanto à atribuição de importância da religião praticada sobre suas respostas. Treze por cento dos respondentes migraram da posição de que a religião não foi importante nas respostas dadas para a afirmação de que ela teve pouca importância. Como a importância da religião foi a variável mais freqüentemente associada com a aceitação dos permissivos legais para aborto ${ }^{12,13}$, se alguma diferença pode ser atribuída ao fato das populações que responderam terem sido distintas, se esperaria que tal diferença se manifestasse no sentido de maior restrição à aceitação das circunstâncias em que o aborto deveria ser legalmente permitido. Porém, como o resultado observado foi o inverso, é possível que as mudanças observadas no sentido de maior abertura dos permissivos legais estejam subestimadas.

As informações descritas neste trabalho devem servir para que a FEBRASGO, principalmente por meio de sua Comissão Nacional Especializada em Violência Sexual e Aborto Previsto na Lei, redobre seus esforços para informar corretamente a seus associados sobre as leis e normas que regulamentam a prática do aborto legal no país. Particularmente relevante é a inclusão da prática do aborto nos casos de gravidez por estupro nos cada vez mais numerosos serviços que dão atendimento de emergência às mulheres que sofrem violência sexual. Algumas delas, que vierem a engravidar, podem aceitar a gestação e levá-la a termo; mas a grande maioria pode ver a gravidez como uma situação intolerável, que faz reviver o trauma do estupro de forma permanente. Essas mulheres merecem que seu direito, amparado pela lei, seja reconhecido. É um imperativo moral e legal que os gineco-obstetras dêem a elas o atendimento que solicitam e ao qual têm direito.

\section{Referências}

1. World Health Organization (WHO) [homepage na Internet]. Unsafe abortion: global and regional estimates of the incidence of unsafe abortion and associated mortality in 2000. 4th ed. Geneve: WHO; 2004 [citado 2007 Fev 10 ]. Disponível em: http://www.who.int/reproductive-health/publications/unsafe abortion_estimates_04/estimates.pdf

2. Monteiro MFG, Adesse L. Estimativas de aborto induzido no Brasil e Grandes Regiões (1992-2005). Rev Saúde Sex Reprod [periódico na Internet]. nov 2006 [citado $2007 \mathrm{Fev} 10$ ]; (26): [cerca de 10p.]. Disponível em: http://www.ipas.org.br/arquivos/ml2006.pdf

3. Colas OR, Andalaft Neto J, Rosas CF, Kater JR, Pereira IG. Aborto legal por estupro. primeiro programa público do país. Bioética. 1994; 2(1):81-5.

4. Faúndes A, Bedone A, Pinto e Silva JL. I Fórum interprofissional para implantação do atendimento ao aborto previsto na lei: relatório final. Femina. 1997; 25(1):69-71, 74-6, 78.
5. Faúndes A, Araújo M, Andalaft Neto, J. Relatório final: VIII Fórum Interprofissional para atendimento integral da mulher vítima de violência sexual. Femina. 2004; 32(6):455-61.

6. Faúndes A, Duarte GA, Andalaft Neto J, Olivatto AE, Simoneti RM. Conhecimento, opinião e conduta de ginecologistas e obstetras brasileiros sobre o aborto induzido. Rev Bras Ginecol Obstet. 2004; 26(2):89-96.

7. Ministério da Saúde. Norma técnica prevenção e tratamento dos agravos resultantes da violência sexual contra mulheres e adolescentes. 2a ed. Brasília: Ministério da Saúde; 2005.

8. Ministério da Saúde. Conselho Nacional de Saúde. Normas de pesquisa envolvendo seres humanos: Res CNS 196/96. Bioética; 1996; 4(2 Supl): 15-25.

9. Lorea RA. Violação de direitos [texto na Internet]. 2005 [citado 2007 Fev 10 ]. Disponível em: http://www.espacovital.com. br/artigoroberto 1803.htm 
10. Gollop TR. Aborto por anomalia fetal incompatível com a vida: características médicas. Cad Juríd. 2001; 2(3):112-5.

11. Macklin R. Against relativism. Cultural diversity and the search for ethical universals in medicine. New York: Oxford University Press; 1999.

12. Faúndes A, Duarte GA, Andalaft Neto A, Osis MD. Aborto induzido: conhecimento, atitude e prática de ginecologistas e obstetras no Brasil. Relatório técnico final [texto na Internet]. 2003. [citado 2007 Fev 10]. Disponível em: http://www.cemicamp.org. $\mathrm{br} /$ relatorios/CAP-MEDICOS-2003.pdf

13. Faúndes A, Duarte GA, Andalaft Neto A, Osis MD. Aborto induzido: conhecimento, atitude e prática de ginecologistas e obstetras no Brasil - Segunda avaliação. Relatório técnico final [texto na Internet]. 2005. [citado $2007 \mathrm{Fev} 10$ ]. Disponível em: http://www.cemicamp.org.br/relatorios/CAPMEDICOS-2005.pdf 